\title{
Managing the complexity of centres of excellence: accommodating diversity in institutional logics
}

\section{Katarina Larsen ${ }^{1}$}

Received: 13 May 2019 / Accepted: 1 October 2019/Published online: 6 December 2019

(C) The Author(s) 2019

\begin{abstract}
This article discusses how Centres of Excellence $(\mathrm{CoE})$ and the existence of several logics in these centres can contribute to the differentiation of the strategic profiles of universities. The study sees research centres as a way to organize research activities in Higher Education Institutions (HEIs) in order to target both excellence but also societal challenges through focused thematic research. It reveals how societal challenges and their interpretation by these centres contribute to the differentiation of the strategic profiles of universities. Studies of centres of excellence programs in Sweden and Japan reveal differences in how their mission is formulated for relevance and excellence. The results indicate that contrasting missions of HEIs are accommodated through the dual logics of these centres relating both to autonomy and industry collaboration. The study shows that long-term funding gives these centres flexibility to set the agenda and focus on their strategic core activities. In other words, a logic of autonomy guides their strategic choices of research activities over the long-run as well as collaborators. Nevertheless, these centres are also developing strategies to cope with dilemmas stemming from the excellence-relevance and evaluation templates that emerge in the nexus of their collaborative ties with industry, government and universities.
\end{abstract}

Keywords Centres of excellence · Research governance - Sweden · Japan · Societal challenges · Institutional logic

\section{Introduction}

This article discusses how Centres of Excellence (CoE) and the existence of several logics in these centres can contribute to the differentiation of the strategic profiles of universities. The particular focus of this study is on mission diversity and the challenges it creates for Higher

Katarina Larsen

larsen@kth.se

1 Division of History of Science, Technology and Environment, KTH Royal Institute of Technology, Teknikringen 74D, 10044 Stockholm, Sweden 
Education Institutions (HEIs) in the context of organizing for diversity through the creation of $\mathrm{CoE}$ in thematic and highly interdisciplinary project teams and research units. For example, $\mathrm{CoE}$ with long-term funding and considerable industry investments, leading to a focus on mission oriented research, allow for flexibility and a high level of autonomy of teams in routines and practices of the centre's research, on the one hand. On the other hand, since these centres are often hosted by academic organizations, they also need to position themselves towards university implemented reforms and audits.

Previous studies of $\mathrm{CoE}$ in the Swedish context have analysed why academics do commercialization and dissemination activities (Wigren-Kristoffersson et al. 2011) and described the Swedish context as a high competitive funding system and its consequences being that funding agencies emphasize organizational impact (Borlaug 2016). As described by Hellström (2013) in an international literature review, typically CoEs are realised through an application approach involving competitive calls, multi-stage selection processes and funding timelines of 5-15 years where up to $50 \%$ matching funding is provided by the host university and/or partner organisations. Selection is conducted by, usually international, academic committees and selection criteria involve programme quality, scientific and societal impact potential, networking and partnerships, national academic visibility, contribution to national goals, and similar value dimensions. Evaluations are conducted by annual financial and operational reviews, mid-term evaluations focusing on outputs and operations, and final evaluations focusing on results and impacts. The evaluations can result in either reduction or increase in funds depending on performance level.

In addition, they face further challenges by having close ties with industry and their related practices of intellectual property, which may challenge the very aim of addressing societal relevant and applicable questions to be available to a broad set of actors. These challenges prompt questions about how organizations create strategies to accommodate several, sometimes conflicting, logics (Thornton and Ocasio 2008; Ocasio et al. 2017). A discussion on how different logics are manifested in HEIs can therefore contribute to reveal competing logics and different strategies to influence, adapt, avoid or resist change (Geschwind 2010), which may provide different types of room for maneuver for the $\mathrm{CoE}$. One point of departure of this study relative to existing literature is to discuss the relation between $\mathrm{CoE}$ and their missions framed in terms of societal challenges in a relevance-excellence nexus. This gives rise to questions about how these centres are defining their core activities in relation to objectives of scientific excellence and societal challenges while being embedded in organizational settings of HEIs.

Before we proceed to the empirical section of the paper, we review previous studies on this topic. We have three objectives. Firstly, we outline the theoretical framework used in this study and discuss concepts such as institutional logics and the organizational field $\mathrm{CoE}$ are positioned in. Secondly, we describe the background as to why CoEs were created and discuss types of funding and evaluation practices. These practices are relevant given that concepts of excellence and societal impact feature prominently in contemporary research policy, namely among research councils and governmental agencies' competitive funding schemes. Thirdly, we outline some of the challenges these centres are facing. In particular, two dilemmas are discussed: the evaluation template dilemma and the excellence-relevance dilemma.

\section{Theory and previous studies}

$\mathrm{CoE}$ are in general focused on high potential/growth areas and can assume forms ranging from the local R\&D group up to regional-level semi-cohesive triple-helix networks consisting of 
hundreds of researchers (Hellström 2011). They can be described in several different ways. For example, they are depicted as networks, forums of interaction, sites for struggles for relevance, or as setting where narratives can contribute to change or stability (Vaara et al. 2016) in a larger organizational setting such as that of universities. Some of the features often emphasized are related to their role in creating networks between university, industry and government in triplehelix networks found in high potential/growth areas (Hellström 2011). Thereby, an analysis of how these semi-autonomous centres contribute to mission diversity in a university setting should also draw on earlier studies of university-industry networks and relations (Balconi and Laboranti 2006) since their relations with industry also have implications for how activities are described and defined by the centres themselves. So far, university and its relations with industry have been analysed both at the institutional level (looking at interactions as being moderated through administrative structures) and at a personal contractual level, which involves formal agreements between individual researchers and firms without direct involvement of universities (Freitas et al. 2013). Little has been said, however, on how relations between semi-autonomous centres with industry and with governmental agencies influence mission diversity in HEIs.

Previous studies that identify and analyse the 'discursive framings' of technology development (e.g. Cairns and Stirling 2014) enable a discussion about the use and interpretation of the relevant concepts to study this topic but also prompt questions about how the boundaries of the specific issues at stake are to be negotiated (which questions that are considered relevant by different actors). To what extent do $\mathrm{CoE}$ represent different logics within universities and are these manifested in the views of their actors? Should they be evaluated and streamlined by the university just as any other unit or is it more valuable to let them create an idiosyncratic organizational identity for promoting cutting edge research? Regarding their autonomy and the relations established with industrial partners, should they be evaluated based on criteria of scientific excellence alone - or should they be examined based on a broader set of criteria to capture different kinds of impact, including those identified by industry partners themselves?

The appropriate theoretical space for discussing existing processes to foster mission diversity, in the context of $\mathrm{CoE}$ hosted by universities, is the study of the logics of decisionmaking in knowledge intensive organizations. One of the most relevant concepts, drawn from organizational studies, is that of 'institutional logics'. In organizational studies, the concept of institutional logics refers to the shared beliefs and practices that guide decision-making within an organizational field. This implies that these practices are organizationally structured, politically defended, and technically and materially constrained (Friedland and Altford 1991). Of particular interest, therefore, is how different logics are manifested and narrated within an organizational context. Studies of organizational practices have a longstanding interest in questions about how organizations create and communicate organizational narratives (Gabriel 2004) as well as their formative events. One example is the concept of organisational sagas, described by Clark (1972, p. 178) as 'a collective understanding of a unique accomplishment based on historical exploits of a formal organization, offering strong normative bonds within and outside the organization. Believers give loyalty to the organization and take pride and identity from it'. In other words, for CoE based at a university, the logics and practices by which the organization acts is dependent on both the external organizational frameworks (e.g.: the regulation by their host institutions), but also by constructs that are culturally or cognitively defined by the centre itself. Both these levels need to be taken into consideration. In organization studies, there is also a distinction between studies of the practices that underlie the different logics within an organization and studies that analyze 
different logics operating within a whole organizational or institutional field. Organizational scholars have argued, however, that an institutional field is not just a collection of organizations and interests operating in the same area of activity, but rather arenas for conflicting interests to be negotiated (Hoffman 1999).

The implication for the analysis of how $\mathrm{CoE}$ are developing their profiles is that there is a link between how activities are organized and the narratives or sagas that are produced. This can, for example, be clearly discerned in internally produced assessment reports where statements of 'contribution to society' are outlined for different science areas and projects. This is of particular interest since some of the examples of centres (from Sweden or Japan) looked at in this study have been explicitly initiated within programs aiming at solving grand societal challenges - while other centres are applying science excellence rhetoric alongside strong collaborative ties with industry. The character of the rhetoric and how it is being negotiated between the centres and their collaborators is in turn influenced by mission statements and strategic choices made in areas of development of emerging science and technology applications in the public-private interface. Therefore the study also draws on previous studies of emerging technologies looking at public-private science boundaries (Colyvas and Powell 2006). Previous studies of hybrid-research environments, including those combining university and industry logics (Thune and Gulbrandsen 2010), are equally relevant to the current study. They raise questions about which types of output measures should be considered in the case of research institutes, including scientific publications (highly cited and/ or published in high impact journals), product development, teaching and education through providing engineers and $\mathrm{PhDs}$ for industry needs, to name just a few.

Previous studies analysing $\mathrm{CoE}$ also discuss evaluations in the context of the principalagent theory (Borlaug 2016). These evaluations are implemented by funding agencies to select the appropriate constellation of academic and industry partners for creating the centre (through assessment by peers) and to monitor activities (through indicators and mid-term evaluations). In addition to this, interim-assessments also represent a communication channel between scientists and research teams (expressed in the centres' self-assessment of their impact) and funding agencies for communicating key aspects of their impact agenda. The mid-term evaluation reports commissioned by funding agencies can then provide insight into how the centres create and communicate their views on impact categories and the way in which these are used in external communication. Some reforms on the Japanese science and technology system (implemented in 2001 and 2004) have been implemented to facilitate the use of midterm objectives in governance of research organisations. This reform also affected funding agencies, such as Japan Science and Technology Agency (JST), becoming Independent Administrative Institutions (IAI) and changed the legal status and governance of both universities and other research performing organisations, such as research institutes. This was geared towards increased accountability, more independent organisations (Vinnova 2009a, p.61) and "to make room for resource allocation to be influenced by the outcome of evaluations of how well each organization has performed in relation to its mid-term objectives and strategies."

However, even if such reforms are aimed at increased accountability and are guided by management objectives in line with New Public Management (NPM) ideals, the study of centres of excellence can reveal a broader narrative of a dual logic guided by ideals of autonomy to ensure scientific excellence but also use a rhetoric of industrial relevance, while they are frequently being hosted by universities. The analysis takes departure in organizational theory and key concepts concerned with co-existing logics. The analysis of governance dilemmas in the next section draws on interviews and review of the centres' own accounts 
of impact categories presented in annual reports and interim evaluations and prompts a discussion about mission diversity and autonomy in the context of centres of excellence that are hosted by universities.

\section{Governance dilemmas}

CoE can then constitute a vehicle for mission diversity of universities, by providing an organizational space (or safe haven) for research development activities and mission oriented science defined by the centre - alone or in dialogue with industrial partners. This resonates with a broader discussion about new skills needed to handle complex problems (Larsen and Gärdebo 2017; Cech 2012; Cumming-Potvin and Currie 2013), social contracts for science and societal relevance (Gibbons 1999; Lubchenco 1998) and international policy discourse of grand challenges and focus on a sustainable development agenda (United Nations 2015; European Commission 2012). A number of specific challenges arise for university management in relation to mission diversity. These can be described as dilemmas between different types of logics within which the organization is operating. For example, there are areas of tension related to the evaluation and implementation of practices for assessing excellence and societal relevance. In the case of $\mathrm{CoE}$ hosted by a university, these differences can be manifested in the centres' mission statements. One example of this is the case of the CoE's programme in Sweden, which was established and assessed using excellence as a criteria and not specifically societal relevance or impact. As a contrast, the Japanese Center of Excellence programme is directly targeting societal challenges including an ageing society as well as innovation and sustainability challenges. This focus on societal challenges is also prevailing in other national settings, such as the US, (National Academy of Engineering 2015) which emphasizes engineering solutions to face future challenges. Furthermore, in the Japanese context, there are some further concerns raised in relation to centres hosted by universities, including the concentration of $\mathrm{CoE}$ in certain universities adding to further hierarchisation pressures in the system. This concern has been recognized at a national level, as outlined in a governmental strategy document (Center for Research and Development Strategy 2016).

Governance of knowledge creation is then a central dimension in the management of HEIs and can encompass several different interpretations. It can be understood as governance of knowledge co-production (Armitage et al. 2011) where several actors in academia and industry are jointly developing new knowledge within a field of research, such as materials sciences. Co-production is alluded to in some studies through the dichotomy between 'two types of knowledge' - experiential knowledge (based on experiences of skilled practitioners) and academic knowledge (Augier and March 2011). Other authors are concerned with the relation between science and technology (Brooks 1994; Patel and Pavitt 1994), emphasizing the interactive nature and how leverage in one domain can enable new discoveries in the other. As an additional example, the EU framework programmes have been created for improving industrial competitiveness and date back to the first framework programme in 1984-87 (Geuna 1999). It is therefore not surprising that the tension between practical and academic knowledge remains as a core dimension of such programmes.

The legitimacy of research activities can also be considered from an actor's perspective, making stakeholders have a say about new technology solutions (Larsen et al. 2011). This has been demonstrated in environmental futures studies using back-casting techniques to discuss alternative solutions with stakeholder groups to ensure broader legitimacy in technology 
choices. The legitimacy aspect of research activities in the light of socially relevant research has also been discussed in studies that emphasize the importance of concepts and metaphors (Flink and Kaldeway 2018). In the case of frontier research, such as innovation in new materials, which is the focus of this study, one point of departure is that this is closely linked to researchers' identities (how they define themselves as researchers) within the context of their interpretation of the materials sciences field. Applied to the level of the research centre, this has implications for the centre's identity. In line with studies of institutional fields, the processes of identity formation take place through the interaction between different interests and logics (Hoffman 1999). This can be fertile ground for a set of governance dilemmas to emerge, with influence over the practices and strategic decisions made by the centres. Two of these, of key relevance for the study of $\mathrm{CoE}$, are outlined below.

- The excellence relevance dilemma: under excellence criteria, CoE apply for (competitive) funding allocation based on scientific excellence, not societal relevance. Nevertheless, the evaluation of the centre's activities is based on the assessment of the impact of its scientific output and on the research activities performed by the centre in collaboration with industrial and international partners.

- The evaluation template dilemma: evaluation practices are mostly influenced by New Public Management (NPM) ideas, where the managerial control by the university is largely influenced by templates (science ranking measurements, innovation surveys etc.) or imported from global university management practices.

In our study, these dilemmas are manifested in how $\mathrm{CoE}$ narrate their societal impact externally, but also with how they create processes and mechanisms for enabling the internal co-habitation of a dual logic, enabling in itself diversity of missions of HEI. Also at the science policy level, these Centres of Excellence, called VinnEx Centres, have a multiple mission, outlined in the evaluation made in 2014 by the Swedish Innovation agency (Vinnova 2014) stating that this particular program should enable collaboration between industry, government, university, research institutes, and other research performing organisations with the aim to develop internationally competitive research environments and networks for user driven research and multidisciplinary science in close collaboration with industry and the public sector. Furthermore, the 2012 governmental bill emphasizes that these centres should carry out basic research and applied research and work towards that the participating companies should be able to benefit from new knowledge and technology.

Nevertheless, in some instances such as in industrial science collaboration that requires the management of intellectual property, these conflicting logics require an active creation of explicit governance practices. In the referred example, there is the need to develop mechanisms to manage intellectual property while ensuring the societal relevance of publicly funded research.

The abovementioned dilemmas for CoE reflect not only a tension between being recognized as excellent evaluation procedures and being industrially relevant, but also recognize that the rhetoric of knowledge production can shift over time. This adds to the struggle of keep being relevant (Bruno et al. 2017). These shifts are also associated with the different interpretations of the concept of science. Merton, in his review of the ethos of science, describes science as: 1) a set of characteristic methods by means of which knowledge is justified; 2) a stock of accumulated knowledge stemming from the application of these methods; 3 ) a set of cultural values governing the activities termed scientific, 4) or any combination of the 
foregoing (Merton 1942, p. 268). These categories range between the practices of science, including scientific methods, to cultural values and norms. The latter category, sometimes referred to as a social contract for science, poses some further challenges for HEIs in their attempts to manage scientific activities in research units that have gained a certain autonomy (through long-term external funding) or the legitimacy of an 'excellence label' by national or international funding agencies, as in the case of CoE.

\section{Empirical approach and methods}

The disciplinary and empirical setting for this study is materials sciences research centres established in university settings in Sweden and in Japan. These centres are referred to as Centres of Excellence $(\mathrm{CoE})$ in the Swedish context. In the Japanese context, the CoE term refers to a series of initiatives and programs established to create centers linked to policy agendas of: i) industry-academia cooperation for innovation ii) promotion of world-level research, and iii) advancement of educational research. The centres studied in this paper cluster under the theme 'promotion of world-level research' (Japan Science and Technology Agency 2017). These initiatives - are found in the WPI - World Premier International Research Center Initiative and have, in the Japanese context, an international dimension, strengthening the national science base also through promoting international collaboration through bilateral agreements with universities abroad. Furthermore, the analysis and evaluation of centres should provide a feedback loop where policy for reforming the CoE-programme is taken into consideration (Center for Research and Development Strategy 2016).

As such, we can conclude that, both in Sweden and Japan, CoEs were created in a policy-context targeted at science excellence and at supporting research environments able to compete with the globally most advanced scientific environments. Our study then draws on the experiences of $\mathrm{CoE}$ as empirical cases to study different approaches to organize research activities in HEIs that target excellence but that also aim at addressing specific societal challenges. One difference between the Swedish and Japanese context is that the Swedish CoE-programme has been complemented with other programmes that has a stronger focus on societal challenges, including programmes in areas of challenge driven innovation (Utmaningsdriven innovation UDI in Swedish) and Strategic innovation areas (Strategiska innovationsområden, SIO, in Swedish), according to interview with representative of the Swedish Innovation Agency. The development taking place since the CoE programme was launched, in 2007, has also been accompanied (or driven) by the successive research bills in 2008 and 2012 (Gov Bill 2008, 2012) in Sweden. The Research Bill from 2008 outlined some expectations, including specifying that "research of high quality can better contribute to the citizen wellbeing, societal development, competitiveness of industry and a sustainable development" (Gov Bill 2012/13:30, translated from Swedish introduction). Furthermore, traits of New Public Management (NPM) can be seen in the Governmental Bill from 2012 referring to the preceding research and innovation bill, which introduced a model with the goal "to reward quality in research and give higher education institution management the incentives to take measures to increase quality and competitiveness in the research undertaken at their institutions."

Despite its organizational setting within the university, these centres are nevertheless guided by specific rules and objectives regarding the definition of their core activities. These are defined within the centre but also in dialogue with funding bodies. With this in mind, these 
centres provide an interesting setting for studies on whether the way research is organized can enable (or disable) certain narratives and how organizational sagas are negotiated between actors in university-industry collaborative settings, but also between university and governmental agencies through evaluation procedures and mechanisms such as mid-term evaluations.

In the first step of the study (2015-2016), we conducted an in-depth study of two CoEs in Sweden. One of the centres had a high focus on combining theoretical modelling with a high level of collaborative efforts with industry. It was therefore considered a suitable case for an indepth analysis of different types of impact categories defined by the centre itself and by the industrial partners collaborating with the centre. The other centre had more direct industry collaboration (but less scientific publications) and was less oriented to incorporate both theoretical models and industry user perspectives. The approach used draws on the analysis of policy documents and centre reports, combined with in-depth interviews with relevant stakeholders from the CoE. This enabled us to paint a richer picture of how the centre is organised and managed. This also minimizes the risk of respondents providing solely anecdotal information, as the document analysis allowed for data triangulation (Bryman and Bell 2007). More specifically, interviews were conducted with centre managers (current and former), senior scientists, doctoral students, industry representatives of companies collaborating with the centre, and governmental officials in charge of the CoE program in Sweden at the Agency Vinnova, a Swedish innovation agency. In the initial stage, 12 interviews were carried out, half of which were interviews with centre representatives including senior researchers, centre managers and doctoral students. The analysis focused on the overarching question 'What different categories of impact are developed in $\mathrm{CoE}$ when managing expectations related to both scientific excellence and societal impact?' The interviews followed a semistructured interview protocol and were performed with each respondent individually, discussing the following themes: What impact is expected to be created?; How is impact defined, organized and managed?; What key mechanisms are involved to support its creation and related challenges?; Does it create impact and scientific excellence?; and What categories of impact have been created in the centre?

In a second step (during spring 2017) an in-depth analysis was carried out in Japanese $\mathrm{CoE}$, also in the area of materials sciences. Interviews were conducted with representatives of five institutes in the area of materials sciences hosted by universities (centres 1-2), nanostructured solar cells (3), nanocellulose (4), and one material sciences government institute (5). These interviews provided a basis for selecting a centre which would serve as a contrasting example to the Swedish CoE studied in depth. Hence, the analysis in Japan focuses on one centre of excellence in materials sciences institutes (centre 1) established in 2007 with the support of the Japanese Ministry of Education, Culture, Sports, Science and Technology (MEXT).

In addition to interviews with five centre representatives in the area of materials sciences, including applications of new materials and related tools and techniques in the areas of nanocellulose materials and nanostructured solar cell technology, interviews were also carried out in governmental funding agencies including National Institute of Science and Technology Policy (NISTEP) and the Japan Science and Technology Agency (JST) coordinating evaluation of centres of excellence programmes. The empirical analysis in this case also included the examination and interpretation of interviews, policy documents and the interim evaluations of centres (Gioia et al. 2013). The following section will discuss some of the results from analysis of the mission statements of the $\mathrm{CoE}$ in relation to the excellence-relevance dilemma and the evaluation template dilemma set out in earlier sections. 


\section{Data analysis}

In the Swedish context, CoE have been established since 2007, under the VinnExcellence programme. In the start-up of the $\mathrm{CoE}$ in Sweden, each centre was granted funds from the Swedish government of SEK $7 \mathrm{M}$ annually over a ten-year period, which constitutes one third of the centres' total funding (additionally, one third is financed by the host university and one third from participating companies). Within this set-up, the centres are under scrutiny and have been assessed continuously from their establishment as well as in mid-term evaluations since 2009. In particular, there has been an effect analysis in 2011, a second evaluation in 2013 and a third evaluation in 2016. This provides a rich source of information about the criteria used for assessing impact and about the responses from the centres in terms of articulating different types of categories of impact. The centres in this programme were subject to a national evaluation in 2017 where the CoE analysed in this study was subsequently granted continued funding together with a sub-set of other centres. The goal is for the centres to become viable and hence survive using other financial means.

In Japan, we analysed CoE funded under the World Premier International Research Center Initiative (WPI) programme, which is promoting the development of research centres in the natural sciences, including material sciences. These centres are also described as 'research bases'. Six of these were established under the WPI program in 2007, and three more were established in 2012. They are recognised as key centres in their fields of research and should contribute to the 'future maintenance and improvement of science and technology standards in Japan'. The annual reports and mission statements of the centres show the diversity of missions pursued by each of these organisations. For example, one centre in the area of material sciences includes both industrial relevance and sustainable society criteria as key aspects in their mission statement (from 2016):

'The mission is to develop tools and competence for fast, intelligent and cost efficient product development for Swedish industry. Continuous scientific breakthroughs are exploited to enable design of materials from atomistic scales to finished products. The improvements of products and processes contribute to a sustainable society.'

The aspect of autonomy is central for CoE in both the Swedish and the Japanese contexts. There are, however, differences in the interpretation of the concept of autonomy, namely regarding the discussion of whom and for what purpose the concept refers to and the identification of which short-term and long-term categories of impact should be used by the researchers active in the centre (see Fig. 1).

The analysis of the short and long term dimensions of impact displays a division of different types of impact categories with different time horizons, as shown on the horizontal axis of Fig. 1. Moreover, the impact categories as described by the collaborators of the CoE in industry includes both more tangible examples (such as skilled scientist or new production processes and tools) as well as categories of more intangible outputs (such as future radical innovation), ranging from shorter to a long-term expected outcome from research and innovation activities of the centre. These categories were derived from the interview study of the CoE in Sweden in combination with a review of interim evaluation reports (Larsen and Nilsson 2016).

To illustrate some of the results from this, we will use examples from three evaluations made of the materials sciences centre analysed in the Swedish context carried out between years 2009-2016 (Vinnova 2009b, 2013, 2016). The evaluation from 2016 includes some 


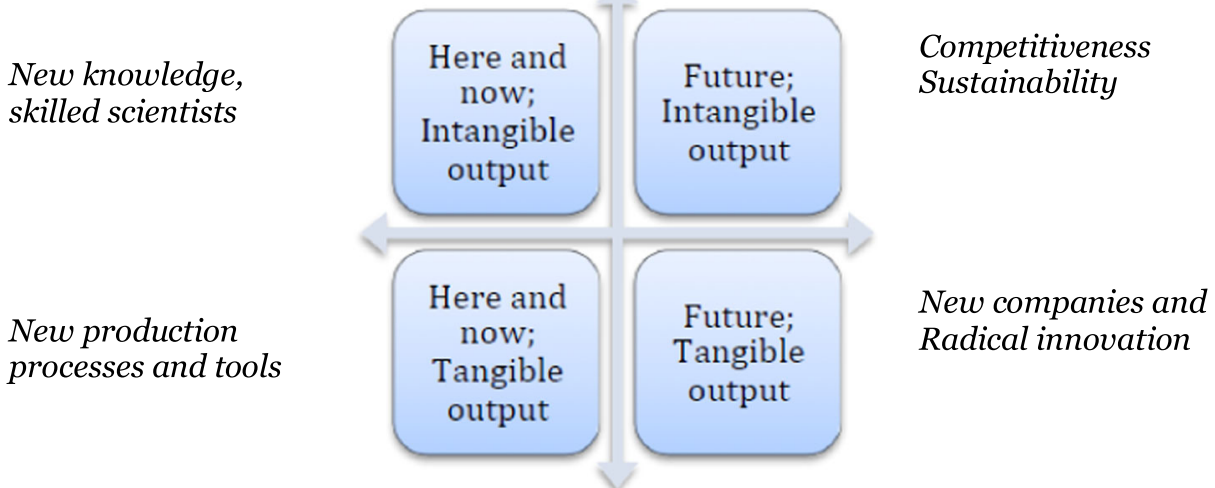

Fig. 1 Impact categories of centres of Excellence (CoE) in Sweden showing examples of tangible and intangible output on the present and future time horizon. Source: Larsen and Nilsson (2016)

statements about societal impact (Vinnova 2016, pp.70-75) relating to both industrial and societal impact, also including in area of material sciences that can be transferred to other sectors to improve gender balance.

"Societal impact through the (named) project is improving gender balance in the materials science area and, through follow-on projects, in 'comparable' sectors..."

This is complemented by an account of other, industrial and societal output including commercialisation successes and benefits to society in more application-oriented and technical terms, focusing on how industrial partners have benefitted from participating in the CoE, including:

- industrial partnership and exchange of knowledge as a particular strength of $\mathrm{CoE}$

- software development

- developing product platforms (that industrial partners can scale up) in areas of cement and steel materials.

These examples of societal and industrial relevance are ranging from impact narratives concerned with changing the structure of gender imbalance in the materials field alongside examples characterized by a 'performance logic' of demonstrated applicability by industrial partners. As shown in interviews with centre management, the processes of providing these examples for the interim evaluations are developed in dialogue between the centre and industrial partners. The virtues of knowledge transfer and interaction with industrial partners was already emphasized in the second evaluation report, (Vinnova 2013, p. 99), through demonstrator activities:

"The Centre has been highly successful in developing new tools and transferring them to the industry partners. It is now crucial that it delivers on their proposed significant design demonstrator as a key focus of Stage 3. In strongly endorsing the Centre's plans to focus on a design demonstrator, the evaluation team is not recommending that the Centre stop pre- competitive tool development; indeed we expect that the demonstrator feeds back into this, creating a virtuous cycle." 
In the first evaluation report (Vinnova 2009b), the dual nature of the research activities and their merits in terms of scientific excellence user relevance was emphasized:

“...the projects are generally geared towards solving identified industrial problems and are hence based on user needs. Nevertheless, the research is of a very high scientific calibre and is very fundamental in nature."

However, the evaluators also raised a concern about the process of selecting new projects:

"The process of selecting new projects does not seem to be well regulated but seems to rely heavily on consensus-oriented discussions among academic partners and in the Board."

To conclude, the results from the review of the interim evaluations in the Swedish context of the $\mathrm{CoE}$ in materials sciences shows a dual character relying on fundamental science but also with a focus on industrial applications and user needs. Although the consensus based model for selecting projects raises some concern, in the first evaluation carried out shortly after the centre was established, a particular strength of the centre emphasized in later evaluations relies on industrial partnership and exchange of knowledge between partners in the centre.

The research centre in focus in Japan in materials sciences displays several different impact categories and associated logics when describing their contribution to society.

Table 1 shows examples of logics adopted by $\mathrm{CoE}$ in materials sciences in Japan. These are:

1. processes of transformation and paradigm shift

2. performance regime - contributions to industrial applications

3. interdisciplinary research and fusion research (interface unit)

4. fundamental understanding through mathematics (mathematics unit)

5. teaching and education of $\mathrm{PhD}$-students (overseas labs in Europe and US)

Table 1 Institutional logics and contributions to society statements in research centres in Japan

\begin{tabular}{|c|c|c|}
\hline & Examples of logics in centres in Japan: & Example of statement about contribution to society: \\
\hline 1) & $\begin{array}{l}\text { Centres providing an infrastructure for } \\
\text { development of materials that can } \\
\text { generate a paradigm shift. }\end{array}$ & $\begin{array}{l}\text { "The materials we investigate have the potential to } \\
\text { supplement the existing materials in revolutionary } \\
\text { advances based on paradigm shift". Development of } \\
\text { new measurement techniques and "quantum } \\
\text { computers which can change current information } \\
\text { technology" }\end{array}$ \\
\hline 2) & $\begin{array}{l}\text { Industry applications } \\
\text { and "Performance regime logics" to } \\
\text { create novel applications }\end{array}$ & $\begin{array}{l}\text { "...materials with their unique, novel properties and } \\
\text { robust chemical structures promise to develop new } \\
\text { families of chemicals, which would be used in } \\
\text { industrial areas." }\end{array}$ \\
\hline 3) & $\begin{array}{l}\text { Interdisciplinary science as fusion } \\
\text { research facilitated by interface } \\
\text { units of "theorists of physics } \\
\text { and chemistry" }\end{array}$ & $\begin{array}{l}\text { "create new materials science by interdisciplinary } \\
\text { research" and "next generation" of materials }\end{array}$ \\
\hline 4) & $\begin{array}{l}\text { Fundamental understanding and role } \\
\text { of theoretical knowledge }\end{array}$ & $\begin{array}{l}\text { "Discovering the same physical principles underlying } \\
\text { different phenomena, and using these principles to } \\
\text { predict new phenomena" }\end{array}$ \\
\hline 5) & $\begin{array}{l}\text { Overseas labs' roles in education of } \\
\text { Japanese students and PhDs }\end{array}$ & $\begin{array}{l}\text { "Training of young researchers in theoretical modelling } \\
\text { of defect in solids and at interfaces." }\end{array}$ \\
\hline
\end{tabular}


The first category entails an expectation of transformation as a result of the research output and impact from the research centre's activities. This transformative perspective can to some extent be compared to the expectation of radical innovation as expressed in the study of a materials sciences centre of excellence in the Swedish context. These expectations of transformation can take place at different levels, from the level of material and product innovations (How can invention of new materials such as Kevlar create new products?) to transforming industry sectors (new materials used in transistors or solar panels) enabling new industry sectors to emerge. The two categories relating to interdisciplinary science and theoretical knowledge are to some extent linked, as theoretical knowledge is expected to also play an important role in the realisation of interdisciplinary science. The fourth category refers to a specific focus on the role of mathematics, and its contribution to society through the development of universal principles but also in practical applications to new materials. This entails how mathematical principles can be applied to find solutions to new problems through interdisciplinary team efforts and is the logic that is most strongly emphasised and also integrated into the structure of the centre which established a mathematics unit.

The fifth category manifests an internationalisation strategy, highly specialized for the particular research of the centre and targeting education and learning for Japanese students in research environments in US and Europe. Furthermore, in the Japanese context, the centres can function as a way to introduce local practices that can support autonomy by younger scholars in a more hierarchical university system. This was one important dimension, mentioned in the interviews with the Japanese CoE. In addition to this, both in Sweden and Japan, there were examples of gender initiatives mentioned by interviewees (e.g.: creating a professional network for women in materials sciences and creating better understanding of conditions for women making careers in science) and by centre representatives, recognizing some structural barriers impeding development at an individual level, but also for the field of research as a whole. Also the fifth category (overseas labs used for training young researchers) combines missions at an individual level by supporting young scholars and a mission targeting the university organization (or the science system) with increased level of internationalisation through measures implemented at the centre level. The aforementioned institute also emphasised the collaboration with foreign companies as it provided both for the exchange of ideas and tools for production processes but also gave the centre a chance to demonstrate (to other firms abroad) that they were suitable collaboration partners. This type of signalling effect can also be found in the industry interviews conducted in the Swedish centres, through a discussion about academic versus industry perspectives on the different missions and impacts arising from the centre. Results from the interviews with the industry representatives show that some of the companies view scientific publications as an important tool for strengthening their own scientific image while others emphasize the importance of supporting the academic researchers' autonomy in selecting novel issues in order to spur new findings that will assist more radical innovations in the future. The process of industry interests informally shifting activities of academic partners to fit their own project objectives has previously been studied as part of the study of phases of collaboration in radical innovation (Van Gils et al. 2015). This is in line with the reasoning of one of the respondents representing the Swedish company being active in the research centre who emphasized that even though the result is rather fundamental, it can quickly be transferred into practice. 


\section{Conclusions and discussion}

This article analyses how Centres of Excellence $(\mathrm{CoE})$ and the existence of several logics in these centres can contribute to the differentiation of the strategic profiles of universities. This also contributes to a discussion about how broader societal and research challenges are interpreted by $\mathrm{CoE}$ and the dilemmas they are facing juxtapose internal strategies with university policy and external assessment practices. On one hand, there is a pressure within HEIs to allow for excellence assessment across units of university, in some cases with funding allocation logics. On the other hand, these $\mathrm{CoE}$ are operating at a global level - comparing themselves to equivalent areas and fields of research and innovation - rather than the research unit at the same university. The results of the study suggest that the level of autonomy of the centre and the high level of specialization in thematic areas is mostly motivated by an international impact performance agenda. This is identified in both national contexts. In Sweden, this is represented by companies acting on a global scale but choosing to collaborate with this specific research centre due to its scientific excellence. These had the upper-hand over arguments based on locally embedded knowledge at a centre based at a national university. One conclusion from the analysis of the Swedish $\mathrm{CoE}$ relates to the internal drivers for change and the processes set up to describe categories of knowledge in relation to the impact agenda of the centre. Even if grand challenges were not explicitly formulated as criteria for funding, the field-work demonstrated the presence of strong drivers for problem solving in dialogue with industrial partners and the creation of collaboration routines to ensure formulation of strategic decisions.

Long-term funding also gives these centres flexibility to define their core activities. It reinforces the autonomous logic that mostly guides their research activities and their strategic choices regarding their areas of operation and collaboration. It makes them less dependent on short-term funding and the coercive measures implemented by university, allowing therefore for the differentiation of strategic profiles among centres and greater diversity within HEIs. Instead, these centres rely mostly on a dialogue and an interactive impact agenda setting with the funding agency.

Moreover, in the Swedish context the CoE programmes were created based, on one hand on the premise of scientific excellence and autonomy, and on the other hand, they were organised in close collaboration with industry partners to ensure user relevance. In that respect their mission statements emphasise the industrial relevance of their research despite the fact that these centres were primarily created based on scientific excellence criteria and are hosted by university organizations. In the Japanese context, the $\mathrm{CoE}$ analysed in this study also provides examples of how their institutional logics communicate the relevance of interdisciplinary teams to ensure industrial relevance and transformation of industrial sectors. This hybrid nature of $\mathrm{CoE}$ makes us return to the concepts of institutional logics and also shows that organisational settings such as these can harbour several logics at once and thereby contribute to increasing diversity in two different ways. Firstly, by creating diversity in terms of strategies (or room for manoeuvre) for the university (as the host organization of the CoE) in collaborative arrangements with industry and dialogue with governmental agencies. Secondly, since these CoE were established based on a logic of 'scientific excellence' rather than the relevance criteria per se, the centre management can gain some autonomy in dialogue with industry partners as well as their host university. This can contribute to balance industry partners' demands for applied oriented research and to develop a more diverse research portfolio that is to a lesser extent dependent of university templates for the evaluation of centres. This further 
emphasizes the importance of autonomy in the setting of CoE in order to achieve the overarching ambition of scientific excellence. One conclusion from the current study is that the governance style of interim evaluations by funding agencies can therefore either curtail autonomy in the CoE setting or contribute to a dialogue about different types of impact and their relevance to stakeholders broadly and to different centre partners in industry and academia. Further studies of these research centres can contribute to a better understanding of how to create suitable conditions for linking mission diversity to transparent career paths for researchers working in interdisciplinary teams in the organizational settings of universities.

Acknowledgements The research was carried out in the project Strategic Action and Response Strategies in a changing Swedish higher education landscape (StARS) and funding is acknowledged from the Swedish Foundation for Social Sciences and Humanities.

Funding Information Open access funding provided by Royal Institute of Technology.

Open Access This article is licensed under a Creative Commons Attribution 4.0 International License, which permits use, sharing, adaptation, distribution and reproduction in any medium or format, as long as you give appropriate credit to the original author(s) and the source, provide a link to the Creative Commons licence, and indicate if changes were made. The images or other third party material in this article are included in the article's Creative Commons licence, unless indicated otherwise in a credit line to the material. If material is not included in the article's Creative Commons licence and your intended use is not permitted by statutory regulation or exceeds the permitted use, you will need to obtain permission directly from the copyright holder. To view a copy of this licence, visit http://creativecommons.org/licenses/by/4.0/.

\section{References}

Armitage, D., Berkes, F., \& Dale, A. (2011). Co-management and the co-production of knowledge: Learning to adapt in Canada's Arctic. Global Environmental Change - Human and Policy Dimensions, 21(3), 995-1004.

Augier, M. \& March, J.G. (2011) The roots, rituals and rhetorics of of change. North American business schools after the second world war. Stanford University Press.

Balconi, M., \& Laboranti, A. (2006). University-industry interactions in applied research: The case of microelectronics. Research Policy, 35, 1616-1630.

Borlaug, S. (2016). Moral hazard and adverse selection in research funding: Centres of excellence in Norway and Sweden. Science \& Public Policy, 43, 352-362.

Brooks, H. (1994). The relationship between science and technology. Research Policy, 23(5), 477-486.

Bruno, K., Larsen, K., \& van Leeuwen, T. H. (2017). Knowledge production at research institutes: Institutional logics and struggles for relevance in the Swedish Institute for Surface Chemistry, 1980-2005. Research Evaluation, 26(4), 337-348.

Bryman, A. \& Bell, E. (2007). Business research methods, 2nd edn, Oxford University Press.

Cairns, R., \& Stirling, A. (2014). 'Maintaining planetary systems' or concentrating global power?' High stakes in contended framings of climate geoengineering. Global Environmental Change, 28, 25-38.

Cech, E. (2012). Great problems of grand challenges: Problematizing Engineering's understandings of its role in society. International Journal of Engineering, Social Justice and Peace, 1(2), 85-94.

Center for Research and Development Strategy (2016) Towards Optimal Development of Centers of Excellence in Japan - For the Formation of Sustainable Strength of Organization and Realization of Innovation -/CRDSFY2016-SP-03. https://www.jst.go.jp/crds/en/publications/CRDS-FY2016-SP-03.html

Clark, B. R. (1972). The organizational saga in higher education. Administrative Science Quarterly, $17(2), 178-184$.

Colyvas, J., \& Powell, W. W. (2006). Roads to institutionalization: The remaking of boundaries between public and private science. Research in Organizational Behavior, 27, 305-353.

Cumming-Potvin, W., \& Currie, J. (2013). Towards new literacies and social justice for engineering education. International Journal of Engineering, Social Justice and Peace, 2(1), 21-37. 
European Commission (2012) Study to assist the European research area board: Investing in research and innovation for grand challenges, Joint Institute for Innovation Policy Version: January 2012.

Flink, T., \& Kaldeway, D. (2018). The new production of legitimacy: STI policy discourses beyond the contract metaphor. Research Policy, 47(1), 14-22.

Freitas, I. M. B., Geuna, A., \& Rossi, F. (2013). Finding the right partners: Institutional and personal modes of governance of university-industry interactions. Research Policy, 42, 50-62.

Friedland, R. and Altford, R. (1991) Bringing society back in: Symbols, practices and institutional contradictions. In The new institutionalism in organizational analysis, Powell, W.W. and DiMaggio, P.J. eds., pp. 232-263. Chicago: University of Chicago Press.

Gabriel, Y. (2004). Myths, stories, and organizations: Premodern narratives for our times. Oxford: Oxford University Press.

Geschwind, L. (2010). Getting pole position: Research strategies in the humanities in Sweden. Tertiary Education and Management, 16(2), 115-127.

Geuna, A. (1999). The economics of knowledge production. Funding and structure of university research. Edward Elgar.

Gibbons, M. (1999). Science's new social contract with society. Nature, 402, C81-C84.

Gioia, D. A., Corley, K. G., \& Hamilton, A. L. (2013). Seeking qualitative rigor in inductive research. Organizational Research Methods, 16(1), 15-31.

Gov Bill (2008). Ett lyft för forskning och innovation. Government Bill 2008/09:50. Government Offices of Sweden, Regeringskansliet. https://www.regeringen.se/rattsliga-dokument/proposition/2008/10/prop.20080950/.

Gov Bill (2012) Forskning och innovation. Government Bill 2012/13:30. Government Offices of Sweden, Regeringskansliet. English summary "Research and Innovation" https://www.government.se/4a556 d/contentassets/9131b15c802a44b9b196d442b498afdb/research-and-innovation\%2D\%2D-a-summary-ofgovernment-bill-2012_13_30.pdf).

Hellström, T. (2011). Homing in on excellence: Dimensions of appraisal in Center of Excellence Program Evaluations. Evaluation, 17/2, 117-131.

Hellström, T. (2013). Centres of excellence as a tool for capacity building: Synthesis report, OECD, http://www. oecd.org/sti/iherd-final-reports.htm.

Hoffman, A. J. (1999). Institutional evolution and change: Environmentalism and the U.S. chemical industry. Academy of Management Journal, 42, 351-371.

Japan Science and Technology Agency (2017) Report on Center of Excellence in Japan, February 2017. Japan Science and Technology Agency (JST), Center for Research and Development Strategy (CRDS).

Larsen, K., \& Gärdebo, J. (2017). Retooling engineering for social justice: The use of explicit models for analytical thinking, critical reflection, and peer-review in Swedish engineering education. International Journal of Engineering, Social Justice, and Peace, 5(1-2), 13-29.

Larsen, K. \& Nilsson, S. (2016). Back to basics - Revisiting rhetoric of competitive research funding allocation and impact agenda in Sweden. Paper presented at conference transforming innovation: Science and Technology for Social Needs. Sussex University, SPRU, September 2016.

Larsen, K., et al. (2011). Environmental scenarios and local-global level of community engagement: Environmental justice, jams, institutions and innovation. Futures: The journal of policy, planning and futures studies, 43(4), 413-423.

Lubchenco, J. (1998). Entering the century of the environment: A new social contract for Science. Science, New Series, 279(5350), 491-497.

Merton, R.K. (1942). The normative structure of Science, chapter 13 in The Sociology of Science. Theoretical and Empirical Investigations, (1973). The University of Chicago press, Chicago and London. Originally published as "Science and Technology in a Democratic Order", journal of legal and political sociology (1942).

National Academy of Engineering (2015) Grand challenges for engineering. National Academy of engineering. Retrieved from http://www.engineeringchallenges.org

Ocasio, W., Thornton, P.T., \& Lounsbury, M. (2017). Advances to the institutional logics perspective. Chapter 19 in The SAGE Handbook of Organizational Institutionalism. 2nd edition, (Eds) greenwood, R., Oliver, C., Lawrence, T.B. and Meyer, R.E. SAGE publishing.

Patel, P., \& Pavitt, K. (1994). The continuing, widespread (and neglected) importance of improvements in mechanical technologies. Research Policy, 23(5), 533-545.

Thornton, P.H. \& Ocasio. W. (2008). Institutional logics. Chapter 3, in The SAGE Handbook of Organizational Institutionalism (Eds) Greenwood, R. et al. Sage Publishing.

Thune, T., \& Gulbrandsen, M. (2010). Institutionalization of university-industry interaction: An empirical study of the impact of formal structures on collaboration patterns. Science and Public Policy, 38(2), 99-107. 
United Nations (2015) Transforming our world: the 2030 Agenda for Sustainable Development. United Nations. Resolution adopted by the General Assembly on 25 September 2015.

Vaara, E., Sondeshein, S., \& Boje, D. (2016). Narratives as sources of stability and change in organizations: Approaches and directions for future research. Academy of Management Annals, 10(1), 495-560.

Van Gils, M., Vissers, G., \& Dankbaar, B. (2015). Industry-science collaboration for radical innovation: The discovery of phase-dependent collaborative configurations. Innovation: Management, Policy \& Practice, 17(3), 308-322.

Vinnova (2016). Third Evaluation of Vinn Excellence Centres. Vinnova Analys VA 2016:01. Swedish Governmental Agency for Innovation Systems.

Vinnova (2014). Results from 18 Vinn Excellence Centres reported in 2012. Vinnova report 2014:02. Swedish Governmental Agency for Innovation Systems.

Vinnova (2013). Second Evaluation of Vinn Excellence Centres. Vinnova report 2013:08. Swedish Governmental Agency for Innovation Systems.

Vinnova (2009a). Priority-setting in Japanese Research and Innovation Policy. Vinnova report 2009:23. Swedish Governmental Agency for Innovation Systems.

Vinnova (2009b). First Evaluation of the second, third and fourth round of Vinnova Vinn Excellence Centres. Vinnova report 2009:34. Swedish Governmental Agency for Innovation Systems.

Wigren-Kristoffersson, C., Gabrielsson, J., \& Kitaawa, F. (2011). Mind the gap and bridge the gap: Research excellence and diffusion of academic knowledge in Sweden. Science and Public Policy, 38(6), 481-492.

Publisher's Note Springer Nature remains neutral with regard to jurisdictional claims in published maps and institutional affiliations. 